\title{
PREVALENCE, PATTERN AND SOCIODEMOGRAPHIC DETERMINANTS OF NEAR MISS OBSTETRICS CASES AND MATERNAL DEATH AT B.P. KOIRALA INSTITUTE OF HEALTH SCIENCES-A TERTIARY CARE CENTER IN EASTERN NEPAL
}

\author{
Madan Khadka ${ }^{1 *}$, Dhruba Kumar Uprety ${ }^{2}$, Rubina Rai ${ }^{3}$
}

\section{Affiliation}

1. Assistant Professor, Department of Obstetrics and Gynaecology, B.P.Koirala Institute of Health Sciences, Nepal

2. Professor, Department of Obstetrics and Gynaecology, B.P.Koirala Institute of Health Sciences, Nepal

3. Associate Professor, Department of Obstetrics and Gynaecology, B.P. Koirala Institute of Health Sciences, Nepal

\section{ARTICLE INFO}

Received : 26 November, 2021

Accepted : 18 January, 2022

Published : 21 February, 2022

(C) Authors retain copyright and grant the journal right of first publication with the work simultaneously licensed under Creative Commons Attribution License CC - BY 4.0 that allows others to share the work with an acknowledgment of the work's authorship and initial publication in this journal.

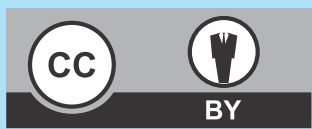

\section{ORA 286}

DOI: https://doi.org/10.3126/bjhs.v6i3.43245

\section{* Corresponding Author}

Dr. Madan Khadka

Assistant Professor

Department of Obstetrics and Gynaecology

B.P. Koirala Institute of Health Sciences, Nepal

Email:khadka4all@gmail.com

ORCID: https://orcid.org/0000-0003-0114-0139

\section{Citation}

Prevalence, Pattern and Sociodemographic Determinants of Near Miss Obstetrics Cases and Maternal Death at B.P. Koirala Institute of Health Sciences-a Tertiary Care Center in Eastern Nepal. Madan Khadka, Dhruba Kumar Uprety, Rubina Rai. BJHS 2021;6(3)16. 1652-1656.

\section{ABSTRACT}

\section{Introduction}

Near misses are a woman who nearly died but survived a complication that occurred during pregnancy, child birth, or within 42 days of termination pregnancy.

\section{Objectives}

This study aims to determine the prevalence, patterns and determinants of maternal near miss and maternal death.

\section{Methodology}

This prospective cross-sectional study was done from August 1, 2014 to July 30,2015 in Department of Obstetrics and Gynecology of B.P. Koirala Institute of Health sciences, Dharan. Cases eligible by five factor scoring system and WHO( World Health Organization)near miss criteria were evaluated. Socioeconomic determinants, prevalence and pattern of near miss and maternal death were assessed.

\section{Result}

A total of 9,727 deliveries were attended during the study period. There were 6307 (71.5\%) vaginal delivery and $2777(28.5 \%)$ caesarean section and 181 perinatal death with total of 9,546 live birth. Total of 162 near misses were identified and 16 maternal death occurred during the study. Maternal near miss rate of 16.6 per 1000 live births and maternal mortality rate of 167 per 100000 live births. Mean age of near miss and maternal death was 25.66 and 25.62 years respectively. Obstetric hemorrhage $(45 \%)$ was the leading cause of near miss and sepsis was the leading cause of death. There were $71.6 \%$ of patient admitted to ICU,48\% were uneducated,55.5\% of near miss occurred in first pregnancy, $92.6 \%$ were unbooked patient and $37 \%$ of near miss event occurred during post-partum period.

\section{Conclusion}

Near miss and maternal death evaluation is an effective tool for delivery of proper health care service and help the policy makers effectively implement the laws in reducing the near miss events and thus the maternal death.

\section{KEYWORD}

Determinant, Maternal death, Near miss. 


\section{INTRODUCTION}

In 2017, each day nearly 810 women died from preventable cause of pregnancy and childbirth. Among all these deaths, 94\% occurred in low and lower middle-income countries. ${ }^{1}$ Nepal being a low income country faces a serious challenge in reducing the maternal mortality rate. Recently near misses have emerged as a useful complement to the investigation of maternal deaths. ${ }^{2,3}$ Maternal mortality traditionally has been the indicator of maternal health all over the world.

Near miss is defined as a woman who survived a complication that occurred during pregnancy, childbirth or, within 42 days of termination of pregnancy. ${ }^{4,5}$ Identification of near miss and its evaluation is essential to evaluate the health care delivery system. Women who develop severe acute complications during pregnancy usually share many pathological and circumstantial factors. While some of these women die, some proportion of them escape death by narrow margin. By evaluating these cases (both "nearmiss" cases and maternal deaths), much can be learnt about the processes in place (or lack of them) for the care of pregnant women.

The study of near miss cases can be used to evaluate the quality of obstetrical care in an institute and to investigate the maternal mortality. Depth study of the cases of nearmiss will help in identifying the deficiency as well as strengths in the provision of obstetrical services in developing countries, and will be useful in improving and strengthening the obstetrical care hence further reducing maternal mortality ratio.

This study aims to identify the near miss obstetrics cases and study the pattern, prevalence and determinants of near miss obstetric cases and maternal death.

\section{METHODOLOGY}

This descriptive, prospective cross-sectional study was conducted at maternity ward of B.P. Koirala Institute of Health Sciences, Dharan from August 1, 2014 to June 30, 2015 after ethical approval from Institutional Review Committee. Purposive sampling technique was applied to include the participants and all the cases who met the criteria of five factor scoring system and WHO near miss criteria were included. ${ }^{5,6}$ Women with complication beyond 42 days of childbirth and non-pregnant women with complication were excluded. Those near misses who failed to survive despite medical treatment and died in our institute were recorded as maternal death. Maternal death outside the institute and brought dead were excluded from the study. The total 178 cases were studied (162 near misses \& 16 maternal deaths). Prevalence and various socio demographic determinants e.g age, booked status (at least 3 minimum ANC visits in this institute), education, occupation, number of antenatal visit, gravidity, WHO predefined risk factors were evaluated. Data were entered into a computer database using Microsoft Excel spreadsheet and SPSS version 16 and statistical analysis was performed. Results were presented as frequencies and percentages.

\section{RESULTS}

A total of 9,727 deliveries were attended during the study period. There were 6307 (71.5\%) vaginal delivery and $2777(28.5 \%)$ caesarean section and 181 perinatal deaths with total of 9,546 live births. Total of 162 near misses and identified and 16 maternal deaths occurred during the study.

\begin{tabular}{|c|c|c|}
\hline Characteristics & $\begin{array}{l}\text { Maternal near } \\
\text { miss (162) }\end{array}$ & $\begin{array}{l}\text { Maternal } \\
\text { death (16) }\end{array}$ \\
\hline \multicolumn{3}{|l|}{ Age } \\
\hline $15-25$ years & $91(56.2 \%)$ & $9(56.25 \%)$ \\
\hline $26-35$ years & $62(38.3 \%)$ & $5(31.25 \%)$ \\
\hline$>35$ years & $9(5.6 \%)$ & $2(12.5 \%)$ \\
\hline \multicolumn{3}{|l|}{ Education } \\
\hline Illiterate & $68(42 \%)$ & $13(81 \%)$ \\
\hline literate & $94(58 \%)$ & $3(19 \%)$ \\
\hline \multicolumn{3}{|l|}{ Occupation } \\
\hline Student & $2(1.2 \%)$ & - \\
\hline Service & $4(2.5 \%)$ & - \\
\hline Housewife & $156(96.3 \%)$ & $16(100 \%)$ \\
\hline \multicolumn{3}{|l|}{ Booked Status } \\
\hline Booked & $12(7.4 \%)$ & $2(12.5 \%)$ \\
\hline Unbooked & $150(92.6 \%)$ & $14(87.5 \%)$ \\
\hline \multicolumn{3}{|l|}{ ANC care } \\
\hline yes & $105(65 \%)$ & $10(62.5 \%)$ \\
\hline no & $57(35 \%)$ & $6(37.5 \%)$ \\
\hline \multicolumn{3}{|l|}{ Gravida } \\
\hline $\mathrm{G}_{1}$ & $32(19.8 \%)$ & $6(37.5 \%)$ \\
\hline $\mathrm{G}_{2}$ & $25(15.4 \%)$ & - \\
\hline $\mathrm{G}_{3}$ & $24(14.8 \%)$ & $1(6.25 \%)$ \\
\hline $\mathrm{G}_{4}$ above & $21(13 \%)$ & $2(12.5 \%)$ \\
\hline Post-partum & $60(37 \%)$ & $7(43.75 \%)$ \\
\hline \multicolumn{3}{|l|}{ Period of gestation } \\
\hline $1^{\text {st }}$ trimester & $40(24.7 \%)$ & $1(6.25 \%)$ \\
\hline $2^{\text {nd }}$ trimester & $16(9.9 \%)$ & - \\
\hline $3^{\text {rd }}$ trimester & $49(30.2 \%)$ & $9(56.25 \%)$ \\
\hline Post- partum & $60(37 \%)$ & $6(37.5 \%)$ \\
\hline \multicolumn{3}{|l|}{ Risk factor } \\
\hline $\begin{array}{l}\text { Molar pregnancy with severe } \\
\text { bleeding }\end{array}$ & $3(1.9 \%)$ & - \\
\hline Severe preeclampsia & $18(11.1 \%)$ & $2(12.5 \%)$ \\
\hline Eclampsia & $26(16 \%)$ & $3(18.75 \%)$ \\
\hline $\begin{array}{l}\text { Sepsis or severe systemic } \\
\text { infection }\end{array}$ & $22(13.6 \%)$ & $4(25 \%)$ \\
\hline Ruptured uterus & $5(3.1 \%)$ & - \\
\hline Surgical/medical condition & $24(14.8 \%)$ & $3(18.75 \%)$ \\
\hline Obstetrics hemorrhage & $45(27.8 \%)$ & $3(18.75 \%)$ \\
\hline $\begin{array}{l}\text { Complication of abortion/ } \\
\text { ectopic }\end{array}$ & $44(27.2 \%)$ & $1(6.25 \%)$ \\
\hline
\end{tabular}

\section{Age group:}

It was found that $56.2 \%$ of near miss and $56.25 \%$ of maternal death were of 15-25 years age group, and the mean age of near miss and maternal death was 25.66 and 25.62 years respectively.

\section{Occupation:}

Among maternal near miss, $96.3 \%$ were housewife,inservice women were $2.5 \%$ and $1.2 \%$ student. In case of maternal death $100 \%$ of them were housewife. 


\section{Booked Status:}

One hundred fifty (92.6\%) were unbooked and $12(7.4 \%)$ were booked and 2 out of 16 (12.5\%) were booked in case of maternal death.

\section{Gravida:}

Among 162 near miss 60 (37\%) were post-partum/post abortion. Out of 162 near miss pregnant women 19.8\%, $15.4 \%, 14.8 \%$ and $13 \%$ were $G_{1} G_{2} G_{3}$ and $G_{4}$ respectively likewise out of 16 maternal death $37.5 \%, 6.25 \%, 12.5 \%$, $43.75 \%$ were $\mathrm{G}_{1,} \mathrm{G}_{3,}$ and $\mathrm{G}_{4}$ and post-partum respectively.

\section{Education:}

Majority of near miss(58\%) had some level of education, however, majority of maternal death(81\%) were illiterate.

\section{Period of gestation:}

Above table shows that the prevalence of maternal near miss was highest i.e, $37 \%$ among post-partum mother, likewise $30.2 \%$ occurred during $3^{\text {rd }}$ trimester, $24.7 \%$ during $1^{\text {st }}$ trimester and $9.9 \%$ during $2^{\text {nd }}$ trimester. Similarly, prevalence of maternal death was high among $3^{\text {rd }}$ trimester women.

\section{Risk factors:}

Obstetric hemorrhage(27.8\%) was the common risk factors for near miss. Among 16 maternal deaths, $25 \%$ was due to sepsis as a leading cause followed by hemorrhage $18.7 \%$, eclampsia $18.75 \%$, medical/surgical condition $18.75 \%$, and one maternal death was due to complication of abortion $6.25 \%$.

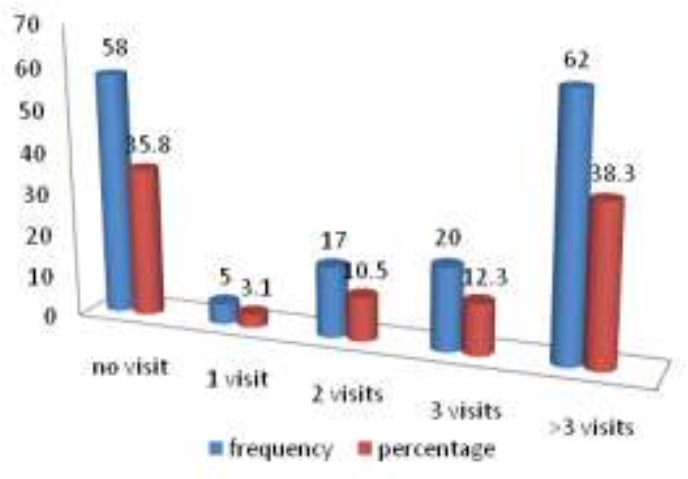

Figure 1: ANC visit for near miss

A total of $38.3 \%$ of near miss had more than 3 visits and $35.8 \%$ of near miss had no ANC visit at all. These ANC visit were either in our institute as a booked case or had visit in other health institute.

Life saving interventions carried for Near miss patients: There were $71 \%$ of near miss in this study who had stayed in ICU( intensive care unit) for further management with mean stay of 3.78 days ranging from 1 to 54 days with ICU admission rate of $1.19 \%$ per delivery. Among ICU admitted patient $51 \%$ were kept for observation, $24 \%$ required vasopressors, $20 \%$ required ventilator support and $6 \%$ required dialysis. $29 \%$ of near miss patient were managed in respective wards without ICU admission.

\begin{tabular}{|c|c|c|c|}
\hline SN & Intensive Care & Frequency & Total \\
\hline 1 & Use of blood products & 110(67.9\%) & 162 \\
\hline 2 & Laparotomy/relaprotomy & $36(22.2 \%)$ & 162 \\
\hline \multirow[t]{5}{*}{3} & Admission to ICU & $116(71.6 \%)$ & 162 \\
\hline & $\checkmark$ Observation & $60(51 \%)$ & 116 \\
\hline & Ventilator support & $24(20 \%)$ & 116 \\
\hline & Vasopressure & $28(24 \%)$ & 116 \\
\hline & Dialysis & $7(6 \%)$ & 116 \\
\hline
\end{tabular}

Table 3 : ICU stay of near misses.

\begin{tabular}{llll}
\hline SN & ICU stay & Frequency & Percentage \\
\hline 1 & No stay & 46 & 28.4 \\
2 & $1-5$ days & 102 & 63 \\
3 & $6-10$ days & 12 & 7.4 \\
4 & $>10$ days & 2 & 1.2 \\
& Total & 162 & 100 \\
\hline & & & Mean=3.78 days
\end{tabular}

Table show that $71.6 \%$ of near miss cases required ICU admission. Mean ICU stay was of 3.78 days and ranging from 1 days to 54 days. Only $1.2 \%$ had ICU stay longer than 10 days. $63 \%$ had ICU stay shorter than 5 days. ICU admission rate was $1.1 \%$ among the total obstetrics cases.

\begin{tabular}{clcc}
\multicolumn{3}{c}{ Table 4: Frequency Distribution of hospital stay } \\
SN & Hospital stay & Frequency & Percentage \\
\hline 1 & $1-5$ days & 49 & 30.2 \\
2 & $6-10$ days & 78 & 48.1 \\
3 & 10 days above & 35 & 21.6 \\
& Total & 162 & 100
\end{tabular}

Mean $=9.03$ days

Table shows that mean hospital stay was of 9 days, ranging from 3 days to 70 days. About $30 \%$ had hospital stay of 1-5 days. $48 \%$ had $6-10$ days and $21 \%$ had hospital stay longer than 10 days.

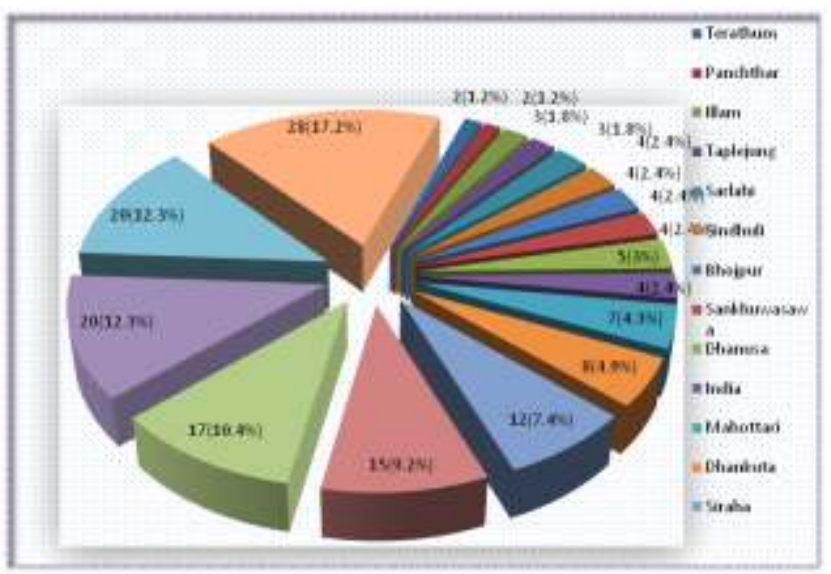

Figure 2: District wise distribution of near misses.

Figure shows most of the near miss patient were from Sunsari district i.e. 28(17.2\%), followed by Morang 20(12.3\%), Saptari 20(12.3\%), Jhapa 17(10.4\%), Udaypur 15(9.2\%), Siraha 12(7.4\%), Dhankuta8(4.9\%), Mahottari 7(4.3\%), Dhanusa 5(3.08\%), Sankhuwasawa 4(2.4\%), 
Bhojpur 4(2.4\%), Sindhuli 4(2.4\%), Sarlahi 4(2.4\%), Taplejung 3(1.8\%), Illam 3(1.8\%), Panchthar 2(1.2\%), Terathum 2(1.2\%), and India 4(2.4\%)

\section{DISCUSSION}

Maternal near miss rate was 16.6 per 1000 live birth and maternal mortality was 167 per 100000 live birth. In a prospective multi center surveillance done in Kathmandu valley, 157 maternal near- miss cases and 26 maternal deaths were identified during a year of study in the 2012 at nine health care facilities with near-miss rate of 3.8 per 1000 live births. ${ }^{7}$ Near miss rate was low as compared to this study. According to NDHS (National Demographic Health Survey) 2011, the median age at first birth is 20.1 years for the youngest cohort of women. Near miss and maternal death were common in age group 15-25 years with median age of 25.66 and 25.62 years respectively. A study in Brazil showed a mean of $25.6 \pm 6.99$ years which was comparable with our study. ${ }^{8}$ Similar study done by Assarag et al. (2014) in Morocco showed mean age of near miss of 29.2 years. ${ }^{9}$

Almost half of near miss patient in our study were uneducated i.e. 42\%. Data from NDHS 2011 shows around $35 \%$ of household women in eastern Nepal are uneducated. Education plays a vital role in the incidence of near miss. Knowledge of danger sign, economic status is associated with education. Higher level of education has delayed first pregnancy, number of ANC visit are relatively higher among educated near miss. Maternal death was seen among $81 \%$ of illiterate. This signifies the need for education among the women to prevent mortality. Study by Assarag et al, in Morocco showed main risk factors of near miss were illiteracy and lack of antenatal care during pregnancy comparable to our study. ${ }^{9}$

Ninety two percentage of near miss in our study were unbooked and nearly $58 \%$ of near miss and $38 \%$ of maternal death had no ANC care. A study in Sagamu, Nigeria showed majority of the cases of near-miss (82.5\%) and maternal death $(88.6 \%)$ were unbooked for antenatal care and delivery in the hospital. ${ }^{10}$

Review of maternal near miss in India showed antenatal care (ANC) to be a major issue. Sixty one percentage of maternal near miss cases did not receive proper ANC and this was comparable with our study. ${ }^{11}$

Most of the near miss patient i.e. 68\% were from plain (Terai) areas, attributed to dense population of these areas. Near miss from the hilly region had delay in referral or had transportation difficulty. Patient from plain areas had early access to health facility, and delay for referral or transportation difficulty was less. Majority of the patient were from Sunsari, Morang, Saptari and Jhapa which are the nearby districts with easy accessibility to our tertiary hospital. There were no significant data on the delay for referral but few patient from remote village had difficulty in access to tertiary care especially women from Sankhuwasawa, Terathum, and Janakpur.

According to NDHS 2011, about 6 in 10 mothers receive antenatal care from a skilled provider. Fifty percent of women make four or more antenatal care visits during their pregnancy, a five-fold increase in the past 15 years. The median duration of pregnancy for the first antenatal visit is 3.7 months.

In this study, $38.3 \%$ of near miss had more than three ANC visits and among them only $7.4 \%$ were booked at this institute. Most of the unbooked near miss patient were supervised at their local hospitals and had been referred to our center following complication of pregnancy.

Thirty seven percentage of near miss event occurred during postpartum period. Most of them were attributed to postpartum hemorrhage. There were $71.1 \%$ of hemorrhagic patient in this study were referred from other health facility. Most of them were referred for the need for blood product unavailable in their setup or due to lack of ICU care. Fifty one percentage of hemorrhagic near miss patient were admitted in ICU and $95.6 \%$ of them had received blood products.

A study by Adeoye et al. showed hemorrhage(41.3\%) followed by hypertensive disorder(37.3\%) as a major determinant of near miss. ${ }^{12}$ Another study by Lotu fo et al. in Sao Paulo showed hemorrhage as a major cause of maternal near miss similar to our study. ${ }^{13}$

Considering the overall rate of admission to intensive care unit (ICU), one can have the first impression of the availability of ICU beds. Very low rates (e.g. less than $0.5 \%$ ) may indicate a shortage of ICU beds. High rates (e.g. Over $3 \%-5 \%$ ) can indicate overuse/unnecessary use of ICU facilities. ${ }^{14}$ Our admission rate $(1.1 \%)$ was neither high nor low. In view of high delivery rate and referral center for complicated cases, our ICU admission rate has been justified.

Seventy one percentage of near miss in this study had stayed in ICU for further management with mean stay of 3.78 days ranging from 1 to 54 days with ICU admission rate of $1.19 \%$ per delivery. Among ICU admitted patient 51\% were kept for observation, $24 \%$ required vasopressors, $20 \%$ required ventilator support and $6 \%$ required dialysis. $29 \%$ of near miss patient were managed in respective wards without ICU admission. Among the near miss managed in wards, $27.2 \%$ of patient had coagulation dysfunction requiring blood transfusion more than 5 pints. $67.9 \%$ of near miss patient required blood products. Majority of near miss patient had stayed in hospital for 6-10 days with mean duration of 9 days ranging from 3 to 70 days.

A study done in Sao Paulo showed the rate of admission to an ICU of $1.6 \%$ of all deliveries with the mean ICU stay was 35 days (range 0-44 days) and the rate of ICU admission was comparable with our study. ${ }^{13}$

Our study showed sepsis as the leading cause of death, 
followed by hemorrhage, eclampsia, medical/surgical condition, and one maternal death was due to complication of abortion. This study was comparable with the study by Rulisa et al. which showed sepsis as a leading cause of mortality. ${ }^{15}$

\section{CONCLUSION}

In developing country like Nepal, women's low economic status, poor obstetric services, and lack of obstetric emergency care during labor has contributed significantly to maternal near miss and maternal death; therefore, emphasis on implementation of Emergency Obstetric Care(EOC) and safe motherhood programme are essential. All women need access to quality maternal health services that can diagnose and manage life-threatening complications. As near miss analysis indicates quality of health care, it is worth presenting in national indices.

\section{LIMITATION OF STUDY}

The study was a prospective observational study done for a period of only 11 months.

\section{ACKNOWLEDGEMENTS}

I would like to acknowledge all the patients, and, faculties and staff of Department of Obstetric and Gynecology of B.P. Koirala Institute of Health Sciences.

\section{CONFLICT OF INTEREST}

None

\section{FINANCIAL DISCLOSURE}

None

\section{REFERENCES}

1. World health organization 2019, Maternal mortality, accessed 19 September2019, available on: <https://www.who.int/news-room/ fact-sheets/detail/maternal-mortality

2. Lumbiganon $\mathrm{P}$, Laopaiboon $\mathrm{M}$, Intarut $\mathrm{N}$, Vogel JP, Souza JP, Gulmezoglu AM, et al. Indirect causes of severe adverse maternal outcomes: a secondary analysis of the WHO Multicountry Survey on Maternal and Newborn Health. BJOG : an international journal of obstetrics and gynaecology. 2014;121 Suppl 1:32-9.https://doi.org/ 10.1111/1471-0528.12647

3. Mantel GD, Buchmann E, Rees H, Pattinson RC. Severe acute maternal morbidity: a pilot study of a definition for a near-miss. British journal of obstetrics and gynaecology. 1998;105(9):98590.https://doi.org/10.1111/j.1471-0528.1998.tb10262.x

4. Pattinson RC, Buchmann E, Mantel G, Schoon M, Rees H. Can enquiries into severe acute maternal morbidity act as a surrogate for maternal death enquiries? BJOG : an international journal of obstetrics and gynaecology. 2003;110(10):889-93.https:// doi.org/ 10.1111/j.1471-0528.2003.03044.x

5. Souza JP, Cecatti JG, Haddad SM, Parpinelli MA, Costa ML, Katz L, et al. (2012) The WHO Maternal Near-Miss Approach and the Maternal Severity Index Model (MSI): Tools for Assessing the Management of Severe Maternal Morbidity. PLoS ONE 7(8): e44129. https:// doi.org/10.1371/journal.pone.0044129

6. Geller SE, Rosenberg D, Cox S, Brown M, Simonson L, Kilpatrick S. A scoring system identified near-miss maternal morbidity during pregnancy. Journal of clinical epidemiology. 2004 Jul 1;57(7):71620.https://doi.org/10.1016/j.jclinepi.2004.01.003

7. Rana A, Baral G, Dangal G. Maternal near-miss: a multicenter surveillance in Kathmandu Valley. JNMA; journal of the Nepal Medical Association. 2013;52(190):299-304.PMID: 24362650
8. Oliveira LC, Costa AA. Maternal near miss in the intensive care unit: clinical and epidemiological aspects. RevistaBrasileira de terapiaintensiva. 2015.https://doi.org/10.5935/0103-507X.20150033

9. Assarag B, Dujardin B, Delamou A, Meski FZ, De Brouwere V. Determinants of maternal near-miss in Morocco: too late, too far, too sloppy? PloS one. 2015;10(1): e0116675.https://doi.org/ 10.1371/ journal.pone.0116675

10. Oladapo OT, Sule-Odu AO, Olatunji AO, Daniel OJ. "Near-miss" obstetric events and maternal deaths in Sagamu, Nigeria: a retrospective study. Reproductive health. 2005;2:9. https://doi.org/ 10.1186/1742-4755-2-9

11. Purandare CN. Maternal near miss review: a way forward. Journal of obstetrics and gynaecology of India. 2013;63(4):213-5.PMID: 24431643 https://doi.org/10.1007/s13224-013-0463-6

12. Adeoye IA, Onayade AA, Fatusi AO. Incidence, determinants and perinatal outcomes of near miss maternal morbidity in Ile-Ife Nigeria: a prospective case control study. BMC pregnancy and childbirth. 2013;13:93.https://doi.org/10.1186/1471-2393-13-93

13. Lotufo FA, Parpinelli MA, Haddad SM, Surita FG, Cecatti JG. Applying the new concept of maternal near-miss in an intensive care unit. Clinics (Sao Paulo, Brazil). 2012;67(3):225-30.https://doi.org/10.6061/ clinics/2012(03)04

14. World Health Organization. Evaluating the quality of care for severe pregnancy complications: the WHO near-miss approach for maternal health. In Evaluating the quality of care for severe pregnancy complications: the WHO near-miss approach for maternal health 2011.

15. Rulisa S, Umuziranenge I, Small M, van Roosmalen J. Maternal near miss and mortality in a tertiary care hospital in Rwanda. BMC pregnancy and childbirth. 2015;15(1):203. https:// doi.org/10. 1186/s12884-015-0619-8 